\title{
A TECNOLOGIA ASSISTIVA SCALA COMO RECURSO PARA PRODUÇÃO DE NARRATIVAS E REGISTRO DE DADOS NAS PESQUISAS EM EDUCAÇÃO: UMA EXPERIÊNCIA COM PESSOAS ADULTAS COM TRANSTORNO DO ESPECTRO AUTISTA
}

\author{
A TECNOLOGIA ASSISTIVA SCALA COMO RECURSO PARA LA \\ PRODUCCIÓN DE NARRATIVAS Y REGISTRO DE DADOS NAS PESQUISAS \\ EN EDUCACIÓN: UNA EXPERIENCIA CON PERSONAS ADULTAS CON EL \\ TRANSTORNO DEL ESPECTRO AUTISTA
}

\begin{abstract}
SCALA ASSISTIVE TECHNOLOGY AS A RESOURCE FOR PRODUCTION OF NARRATIVES AND DATA REGISTRATION IN RESEARCH IN EDUCATION: AN EXPERIENCE WITH ADULTS WITH AUTISM SPECTRUM DISORDER
\end{abstract}

Ivanise Gomes de Souza BITTENCOURT ${ }^{1}$

Neiza de Lourdes Frederico FUMES ${ }^{2}$

RESUMO: O presente artigo tem por objetivo apresentar o Sistema de Comunicação Alternativa para Letramento de Pessoas com Autismo (SCALA) enquanto recurso de produção de narrativas e registro de dados nas pesquisas em educação. Essa tecnologia assistiva foi desenvolvida em 2009 por pesquisadores da Universidade Federal do Rio Grande do Sul (UFRGS) e nos anos subsequentes adquiriu novas versões, acrescentando um módulo de narrativas visuais para a construção de histórias nas plataformas web e android/tablet. Através do módulo de narrativas visuais é possível que participantes de pesquisas, principalmente com déficits de comunicação, construam histórias relacionadas a diversos objetos de estudos de pesquisa em educação. Esse estudo foi desenvolvido, entre os meses de abril e maio de 2016, com quatro participantes com Transtorno do Espectro Autista (TEA), com idades entre 30 e 36 anos, sendo uma do sexo feminino e três do sexo masculino. Os resultados evidenciaram o SCALA como uma ferramenta relevante de investigação em educação, especialmente na realização de pesquisas envolvendo alunos com TEA, pois permitiu conhecer as percepções dos participantes quanto aos professores, escola e amigos, seus interesses e dificuldades, experiências positivas e negativas e sentimentos quanto à interrupção do processo de escolarização.

PALAVRAS CHAVE: Tecnologia assistiva. Educação. Transtorno do Espectro Autista.

RESUMEN: Este artículo tiene por objetivo presentar el Sistema de Comunicación Alternativa para Letramento de Personas con Autismo (SCALA) como recurso de producción de narrativas y registro de datos en las investigaciones en educación. Esta

\footnotetext{
${ }^{1}$ Universidade Federal de Alagoas (UFAL), Alagoas - Brasil. Docente do Curso de Enfermagem da UFAL. Doutoranda em Educação pelo Programa de Pós-Graduação em Educação UFAL. E-mail: ivanisegsb@gmail.com

${ }^{2}$ Universidade Federal de Alagoas (UFAL), Alagoas - Brasil. Docente do Programa de Pós-Graduação em Educação da Universidade Federal de Alagoas. Doutora em Ciências do Desporto e Educação Física. E-mail: neiza.fumes@cedu.ufal.br
} 
tecnología asistida fue desarrollada en 2009 por los investigadores de la Universidad Federal de Río Grande do Sul (UFRGS) y en los años subsiguientes adquiriu nuevas versiones que presentan un módulo de narrativas visuales para la construcción de históricas en plataformas web y android/tablet. Através del módulo de narrativas visuales es posible que los participantes de la investigación, principalmente con los déficits de la comunicación, construyen historias relacionadas a diversos objetos de estudios de investigación en educación. Este estudio fue desarrollado, entre los meses de abril y mayo de 2016, con cuatro participantes con el Transtorno del Espectro Autista (TEA), com idades entre 30 y 36 años, siendo una do sexo femenino y tres do sexo masculino. Los resultados muestran el SCALA como una herramienta relevante de investigación en educación, especialmente en la realización de estudios relacionados con alumnos com el TEA, porque permitiu conocer percepciones de los profesores, escuela e amigos, sus intereses y dificultades, experiencias positivas y negativas y sentimentos relacionados con la interrupción del proceso de escolarización.

PALABRAS CLAVE: Tecnologia assistiva. Educación. Transtorno del espectro autista.

ABSTRACT: The present article aims to present the Alternative Communication System for Literacy of People with Autism (SCALA) as a resource for producing narratives and recording data in education research. This assistive technology was developed in 2009 by researchers from the Federal University of Rio Grande do Sul (UFRGS) and in the following years acquired new versions by adding a module of visual narratives for storytelling on the web and android / tablet platforms. Through the module of visual narratives it is possible that research participants, mainly with communication deficits, build stories related to several objects of research studies in education. This study was developed between April and May 2016, with four participants with Autism Spectrum Disorder (ASD), aged between 30 and 36 years old, one female and three male. The results evidenced SCALA as a relevant research tool in education, especially in carrying out research involving students with ASD, since it allowed to know the participants' perceptions regarding teachers, school and friends, their interests and difficulties, positive and negative experiences and feelings Interruption of the schooling process.

KEYWORDS: Assistive technology. Education. Autistic spectrum disorder.

\section{Introdução}

Participantes de pesquisas, que possuem déficits de comunicação, podem apresentar dificuldades em contar histórias ou produzir narrativas de vida pela não apropriação da linguagem oral.

O SCALA, uma tecnologia assistiva, desenvolvida para pessoas com TEA ou com outros transtornos, possibilita o apoio no processo comunicativo entre pesquisador e participantes com déficits de comunicação, de forma suplementar, bem como enfatizaram Passerino e Bez (2015) quanto aos progressos quando se aplica algum 
sistema de comunicação alternativa, para participantes com essa especificidade, promovendo a autonomia destes em situações de comunicação e de pesquisa. A Comunicação Alternativa (CA), "pretende suplementar, complementar, aumentar ou dar alternativas para efetivar a comunicação de pessoas com déficits nessa área" (PASSERINO; BEZ, 2015, p. 30).

O seu módulo de Narrativas Visuais, destinado para a construção de histórias, através de imagens e outros elementos que disponibiliza, permite que participantes construam suas histórias a partir de temáticas diversas relacionadas a diferentes objetos de estudos de pesquisa em educação. Configurando-se, inclusive, como um recurso de produção de narrativas e registro de dados, realçando a necessidade de assegurar que todos os aspectos dos métodos de produção de dados sejam adequadamente diferenciados para abordar a realidade de pessoas com TEA em virtude das suas especificidades (PREECE; JORDAN, 2010).

Nesse sentido, este artigo tem por objetivo apresentar o SCALA enquanto recurso de produção de narrativas e registro de dados nas pesquisas em educação, através de uma experiência com pessoas adultas com TEA.

\section{O SCALA}

O SCALA possui um módulo de Narrativas Visuais, destinado para a construção de histórias, através de imagens e outros recursos, possibilitando: 1) A CA através de Narrativas Visuais (imagens) na construção de histórias pelos participantes, de forma a promover a comunicação e produção de narrativas de vida; e 2) Recurso de produção, registro e análise de dados das imagens das histórias; permitindo, desse modo, compor as produções de campo de pesquisas, como orientaram Clandinin e Connelly (2015) quanto às formas de registro dos dados.

As possibilidades de uso do SCALA não se limitam apenas a participantes com déficits de comunicação, sendo extensivo aos oralizados, pois o processo de construção de histórias e captação de imagens relacionadas proporciona riqueza de detalhes de suas vidas, anteriormente não relatadas na técnica de uma entrevista. Portanto, para compreender o SCALA, apresentam-se seus detalhes.

O SCALA (http://scala.ufrgs.br), Figura 1, tem como objetivo apoiar o desenvolvimento do letramento de pessoas com autismo (BEZ et al., 2013). O primeiro protótipo foi desenvolvido em 2009, por pesquisadores do grupo de pesquisa 
Tecnologia em Educação para Inclusão e Aprendizagem em Sociedade (TEIAS) da Universidade Federal do Rio Grande do Sul (UFRGS), para computadores desktop, e nos anos subsequentes adquiriu novas versões para funcionar na web e em dispositivos móveis, como celular, tablets, entre outros (BEZ, PASSERINO, 2012).

Figura 1: SCALA - Página Inicial

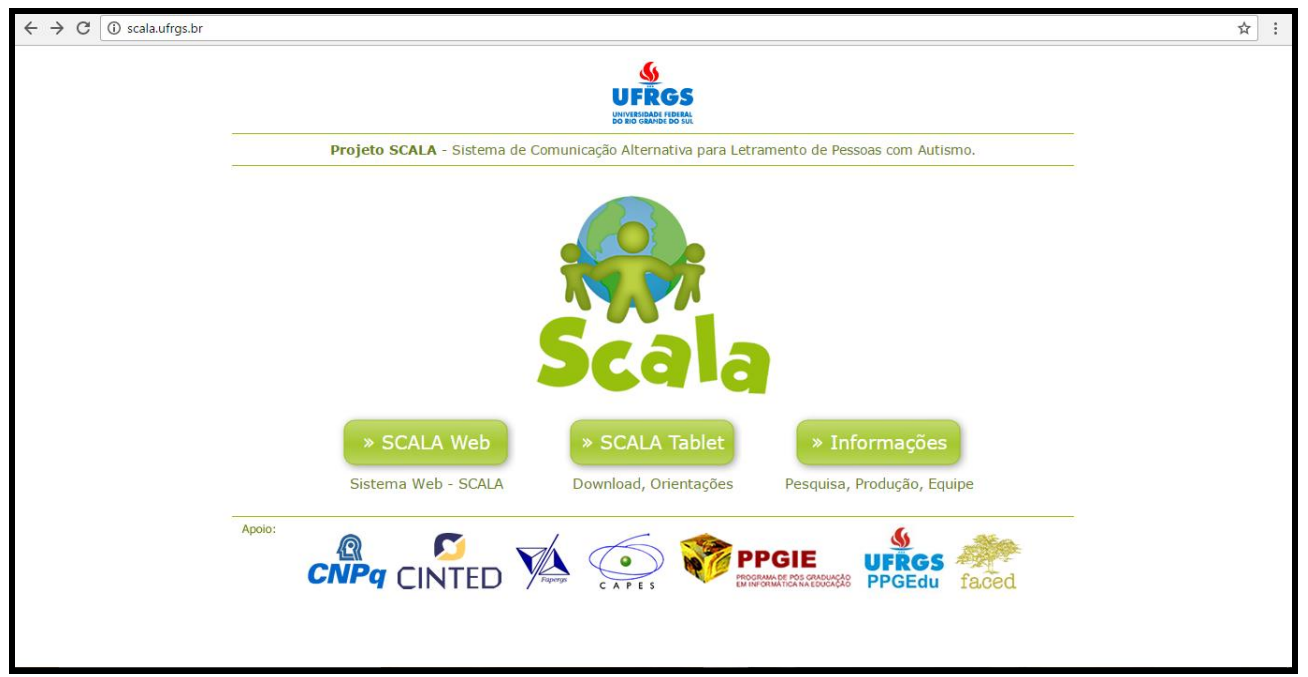

Fonte: http://scala.ufrgs.br

O software é gratuito, seu conteúdo é aberto e livre, com necessidade de um cadastro prévio, a partir da aceitação dos termos de uso do sistema, como pode ser visto na Figura 2:

Figura 2: SCALA - Página de Cadastro e Login

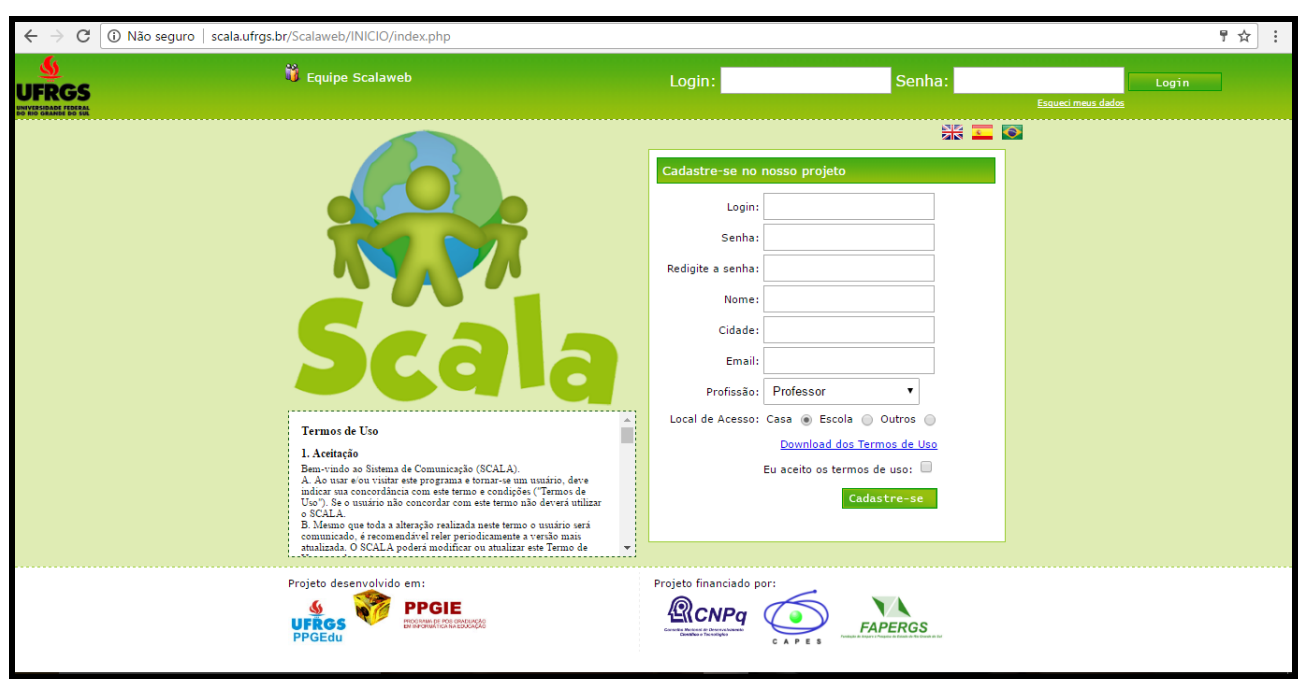

Fonte: http://scala.ufrgs.br/Scalaweb/INICIO/index.php 
Em 2011, o SCALA 2.0 iniciou a proposta multiplataforma, possuindo dois módulos, o Prancha e o de Narrativas Visuais (PASSERINO et al., 2013), como demonstrado na Figura 3:

Figura 3: SCALA - Módulos Prancha e Narrativas Visuais

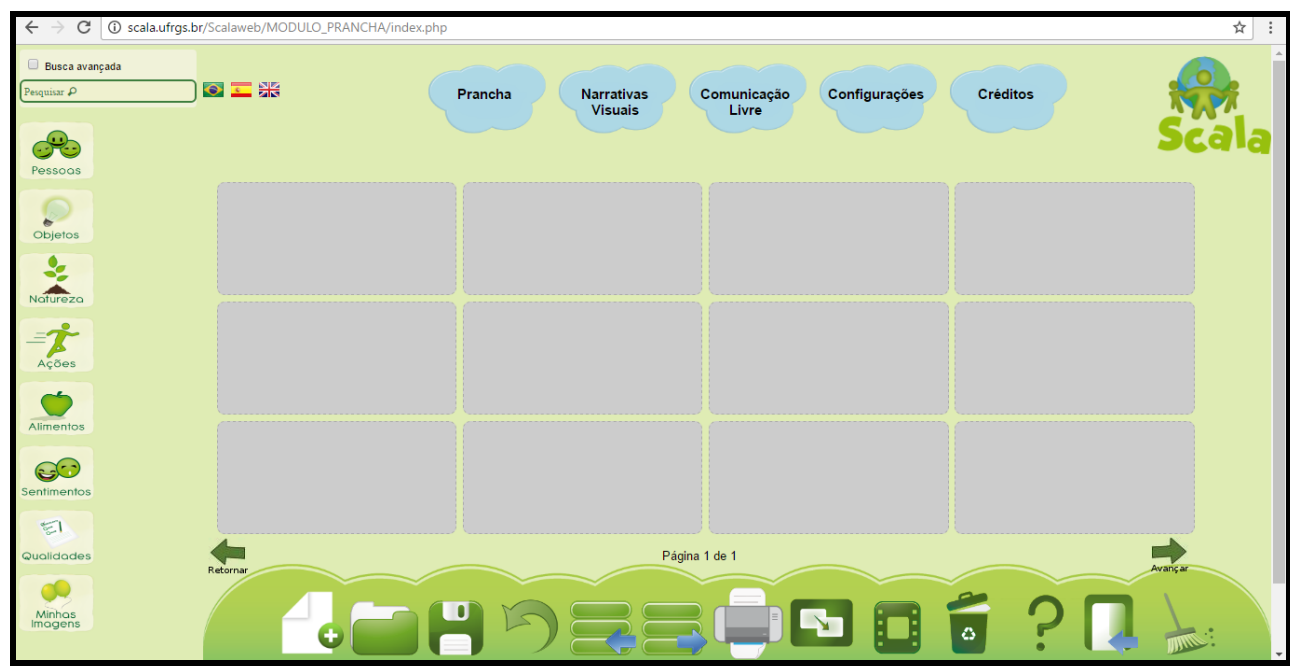

Fonte: http://scala.ufrgs.br/Scalaweb/MODULO_PRANCHA/index.php

As Pranchas de comunicação, de acordo com Passerino et al. (2013), são recursos de tecnologia assistiva que facilitam a comunicação entre pessoas com déficit de comunicação e outros participantes, além de contribuir para a interação e autonomia destes. O módulo Narrativas Visuais é apresentado na Figura 4:

Figura 4: SCALA - Módulo Narrativas Visuais

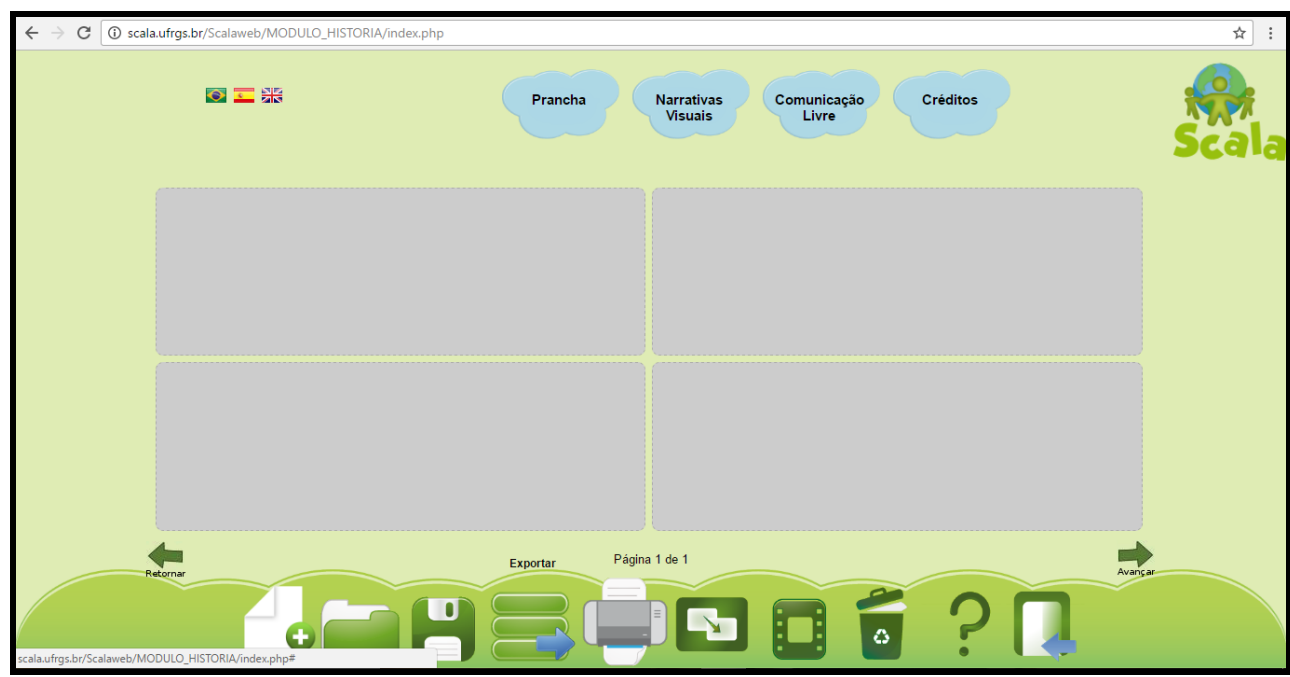

Fonte: http://scala.ufrgs.br/Scalaweb/MODULO_HISTORIA/index.php 
O modelo demonstrado na figura 5 serve para construção de histórias, o qual apresenta flexibilidade na elaboração e permite a criação de narrativas simples:

Figura 5: SCALA - Módulo História

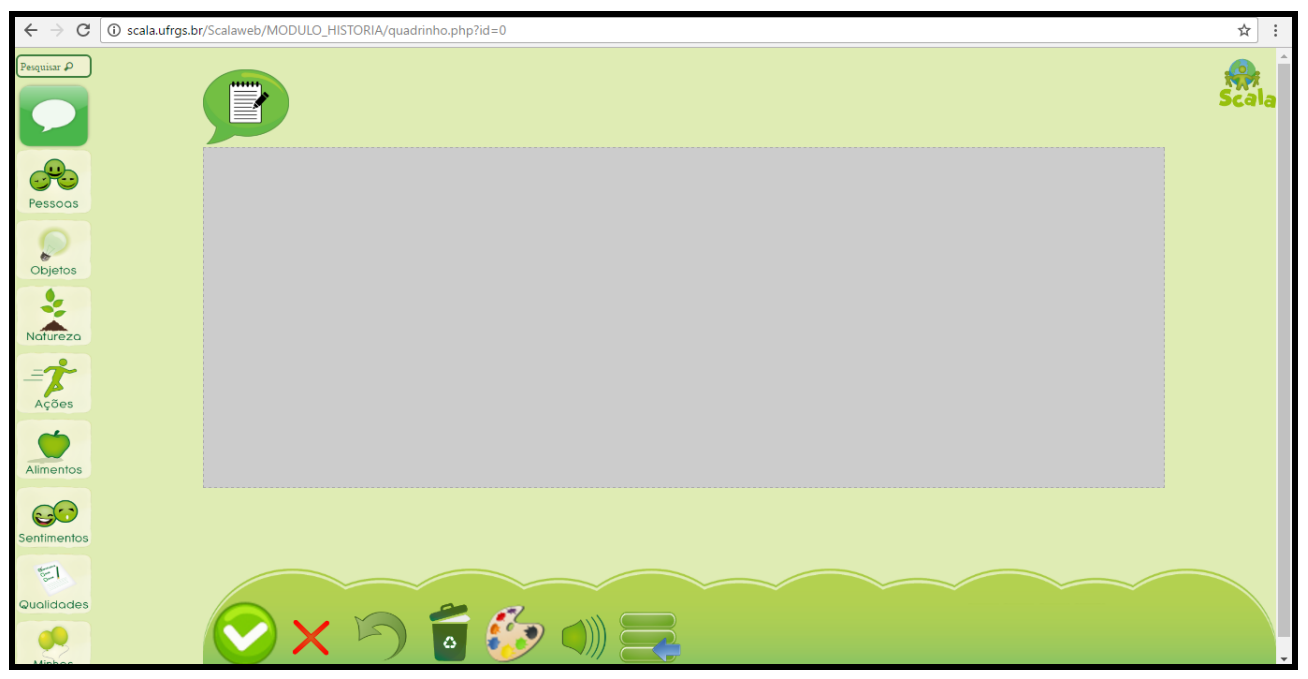

Fonte: http://scala.ufrgs.br/Scalaweb/MODULO_HISTORIA/quadrinho.php?id=0

Os seus símbolos pictográficos são propriedade de Catedu (http://catedu.es/arasaac/), sob as licenças GNU e Creative Commons; a plataforma conta com aproximadamente 5.000 símbolos para atender à diversidade cultural e à especificidade do autismo, conforme descrevem Bez e Passerino (2015).

Suas imagens são divididas nas categorias (pessoas, objetos, natureza, ações, alimentos, sentimentos, qualidades), além do ícone "minhas imagens", onde o usuário pode inserir imagens próprias no sistema (PASSERINO et al., 2013), como pode ser visto nas Figuras 6 e 7. Todas as imagens também possuem legendas que as identificam.

Figura 6: SCALA - Categorias das imagens

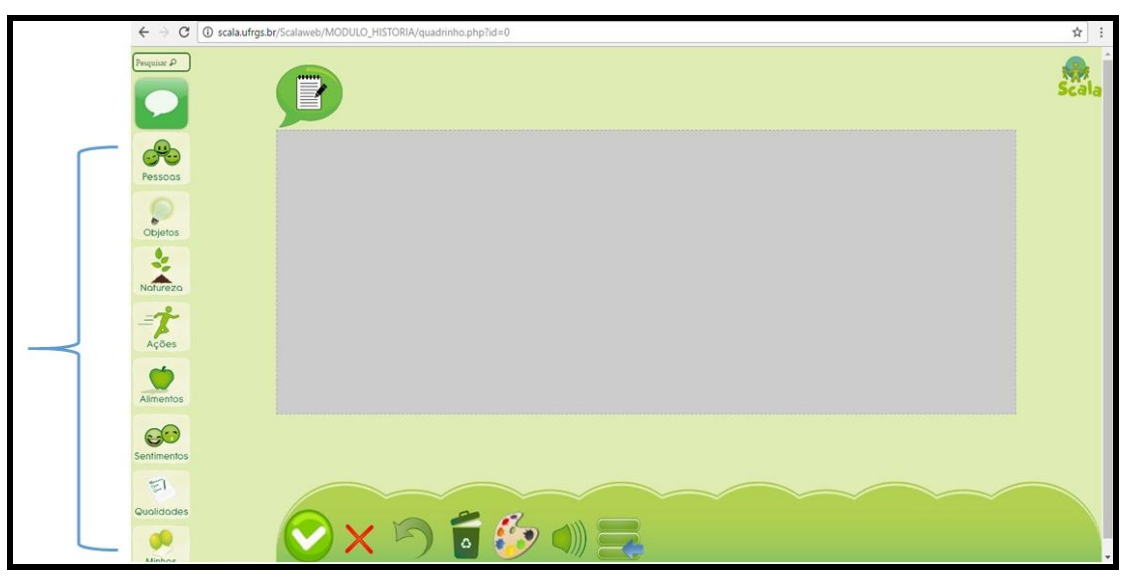

Fonte: http://scala.ufrgs.br/Scalaweb/MODULO_HISTORIA/quadrinho.php?id=0 
Figura 7: SCALA - Imagens das Categorias

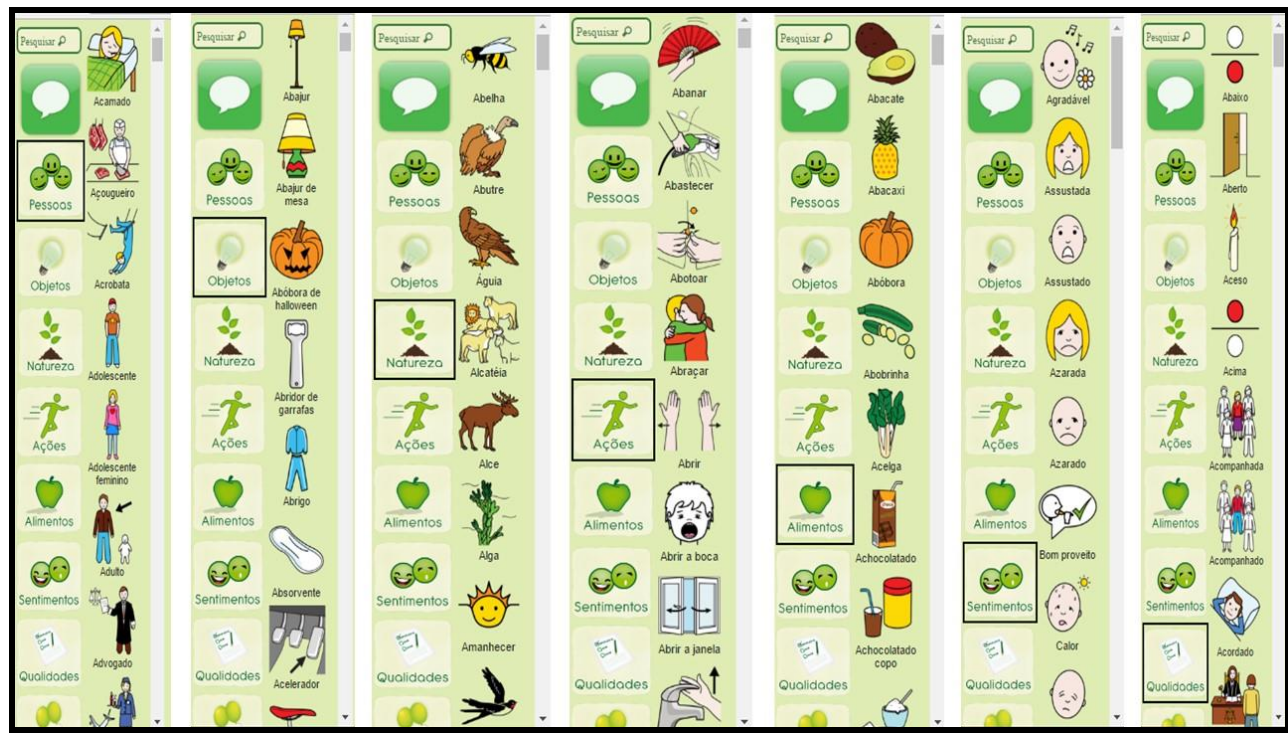

Fonte: http://scala.ufrgs.br/Scalaweb/MODULO_HISTORIA/quadrinho.php?id=0

Este módulo disponibiliza diversificados layouts, inserção de imagens e edição das mesmas, escolha de cores e cenários (PASSERINO et al., 2013), como demonstrado na Figura 8:

Figura 8: SCALA - Cenários do SCALA

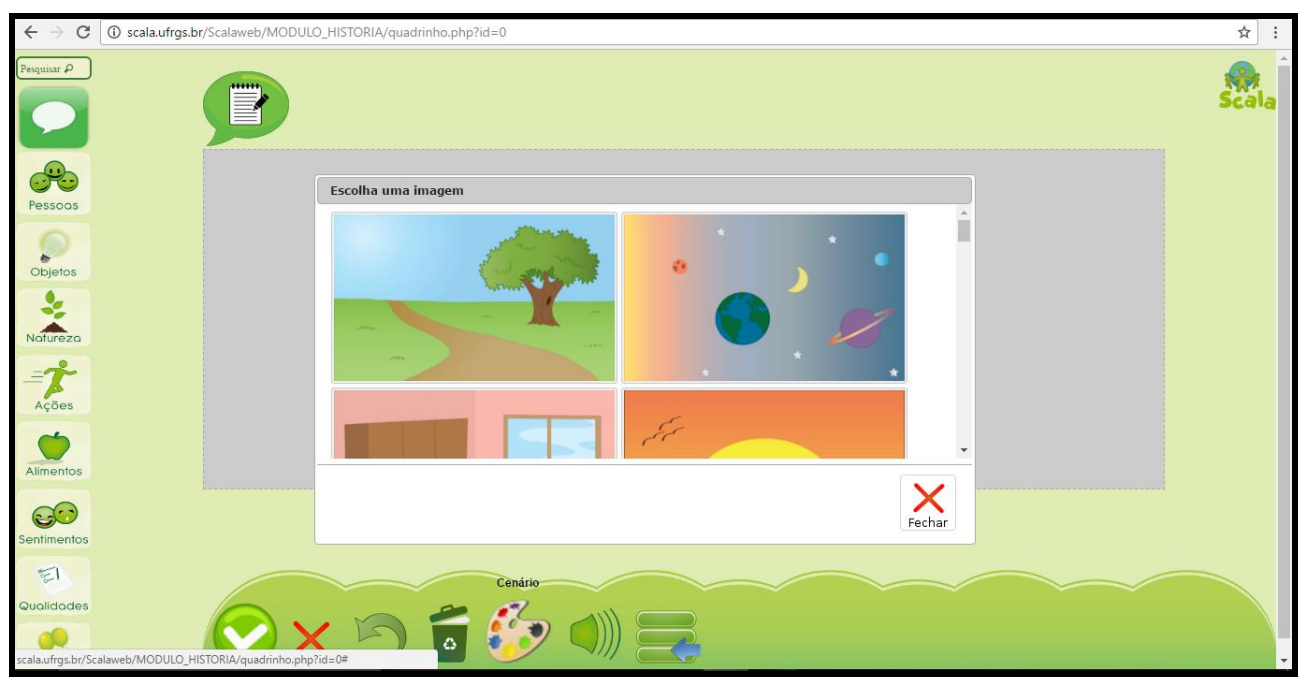

Fonte: http://scala.ufrgs.br/Scalaweb/MODULO_HISTORIA/quadrinho.php?id=0

São 24 cenários disponíveis para escolha na construção das histórias, de acordo com a Figura 9: 
Figura 9: SCALA - Cenários disponíveis

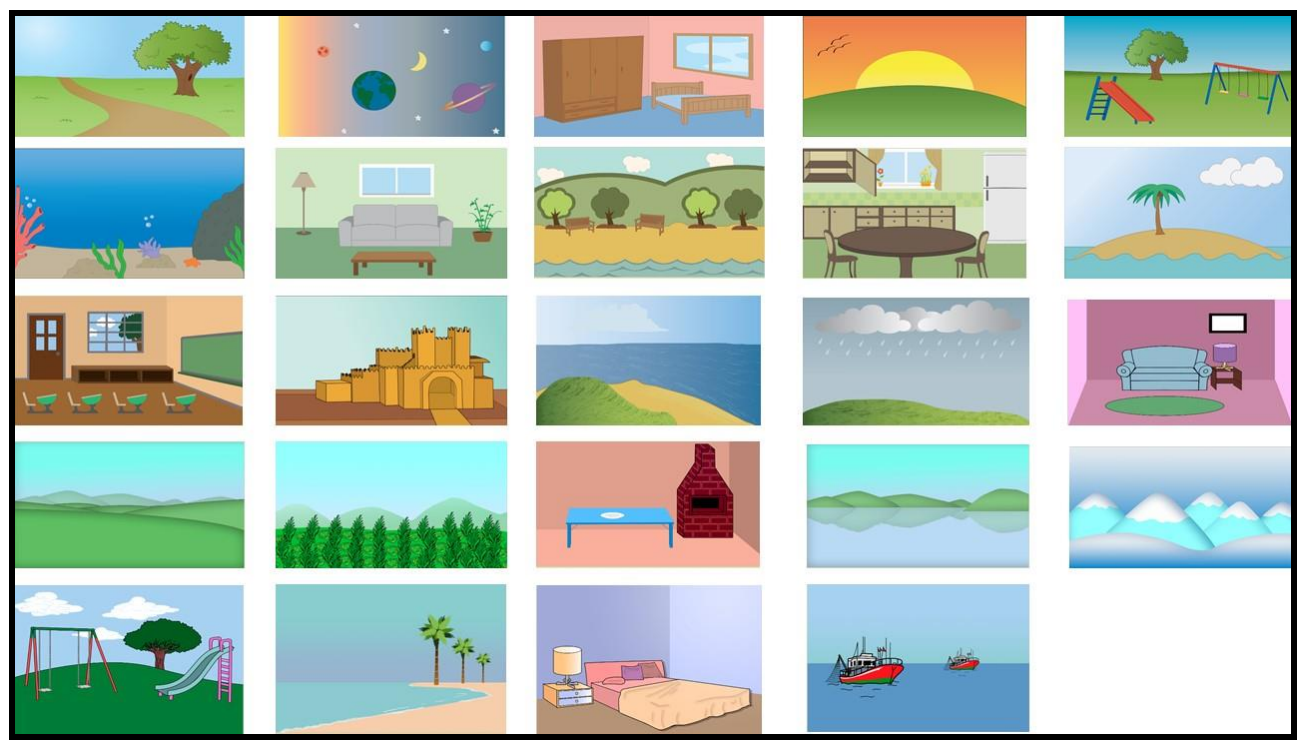

Fonte: http://scala.ufrgs.br/Scalaweb/MODULO_HISTORIA/quadrinho.php?id=0

\section{Método}

Trata-se de um estudo com abordagem qualitativa, sendo esta indicada por Hickey, Crabtree e Stott (2017) como um importante caminho para facilitar o estudo aprofundado das experiências e opiniões de adultos com TEA. Dillon, Underwood e Freemantle (2014) reforçam que é errônea a suposição de que pessoas com TEA são incapazes de envolverem-se na autorreflexão, pois alguns são capazes de pensar sobre situações dentro e fora da escola, demonstrando uma autoconsciência que historicamente não lhes é associada.

Essa pesquisa foi aprovada pelo Comitê de Ética em Pesquisa da UFAL sob o parecer $\mathrm{n}^{\mathrm{o}}$ 1.340.279, em novembro de 2015. Foram respeitados os procedimentos éticos, estabelecidos na Resolução 466/12, tendo sido apresentado o Termo de Consentimento Livre e Esclarecido (TCLE) para os participantes com TEA.

Utilizou-se o SCALA entre os meses de abril e maio de 2016, com quatro participantes com TEA com idades entre 30 e 36 anos, sendo uma do sexo feminino e três do sexo masculino, para que construíssem suas histórias quanto à escola e posteriormente a narrassem. Essas entrevistas foram realizadas em momento único, presencial e individual, a sós com a pesquisadora.

De forma a preservar a identidade dos participantes com TEA, lhes foi solicitado escolher um nome fictício. Portando, nos dados da pesquisa eles são representados como: Felipe, Nek, Juliana e Melvin. 
As entrevistas foram transcritas logo após a realização das mesmas, sob o cuidado prévio de qualquer eventualidade que pudesse danificar os arquivos dos áudios. Quanto à exposição das vivências, adotou-se a orientação de Silva e Trentini (2002) quanto à apresentação das narrativas orais, reelaborando as entrevistas, transformandoas em relatos contados pelo pesquisador e também escrevendo trechos de narrativas, usando a linguagem da pessoa que narrou.

\section{O uso do SCALA}

Para o uso do módulo de Narrativas Visuais (construção de histórias), realizouse, inicialmente, pela pesquisadora, o cadastro de cada participante no SCALA.

Posteriormente, através de encontros individuais, únicos e previamente agendados com os participantes com TEA, em locais variados de acordo com suas disponibilidades, essa ferramenta lhes foi apresentada, em um tempo de cerca de trinta minutos, para que conhecessem os seus recursos e formas de manuseio, para a construção das histórias sobre as suas vivências e significações quanto aos seus espaços de vida, a si, o autismo e o futuro.

Cada participante construiu suas histórias, sem interrupção da pesquisadora, que apenas forneceu o seguinte tema: "A escola". A construção da história era iniciada com a escrita do tema na prancha do módulo de Narrativas Visuais, por cada participante, depois pela sua escolha do cenário através do que eles relacionavam com o tema. Após isso, cada participante prosseguiu abrindo os ícones de todas as categorias, de forma sequencial, verificando todas as imagens e legendas que cada categoria disponibilizava, e escolhendo cada imagem, que eles também relacionavam com as suas vivências e significações. Nenhum participante apresentou dificuldades quanto ao manuseio do SCALA durante essa atividade de construção de histórias que os fizessem necessitar do apoio/intervenção da pesquisadora.

Dessa forma, com duração mínima de cinquenta minutos e máxima de duas horas e trinta minutos, nos meses de maio e junho de 2016, realizou-se a atividade junto ao SCALA.

Imediatamente após o término de todas as histórias construídas, em virtude de se encontrarem preservados os pensamentos que conduziram essas produções, os participantes foram convidados a narrar sobre o conteúdo da história, os personagens inseridos e os significados das imagens. Os participantes com TEA, a partir de cada 
história construída, descreveram narrativamente os seus conteúdos e significados, sob o tempo, livremente determinado pelos próprios, de mínimo de dezoito minutos e máximo de vinte e seis.

As narrativas dos participantes foram transcritas e apresentadas de acordo com o que se descreve no item a seguir.

\section{As narrativas de vivências escolares de pessoas adultas com TEA através do uso do SCALA}

Os participantes com TEA participantes do estudo ingressaram na escola regular em idades variadas: Felipe (por volta dos dois anos e meio), Nek (com um ano e oito meses), Juliana (aos três anos) e Melvin (aos cinco anos), com trajetórias principalmente por escolas privadas, com exceção de Felipe, que a partir da quarta série seguiu somente por escolas públicas. Todos vivenciaram consecutivas mudanças de escola, por diversos motivos, mas principalmente relacionados à fragilidade do sistema escolar em lidar com eles, em suas diferenças. Possuíam escolaridades diferentes, tais como: Felipe (ensino superior completo); Nek (ensino superior incompleto); Juliana (ensino médio completo) e Melvin (ensino fundamental incompleto).

Nas representações dos participantes quanto à escola, simbolizaram as suas vivências nesse espaço de acordo com a Figura 10:

Figura 10: A escola para os participantes com TEA

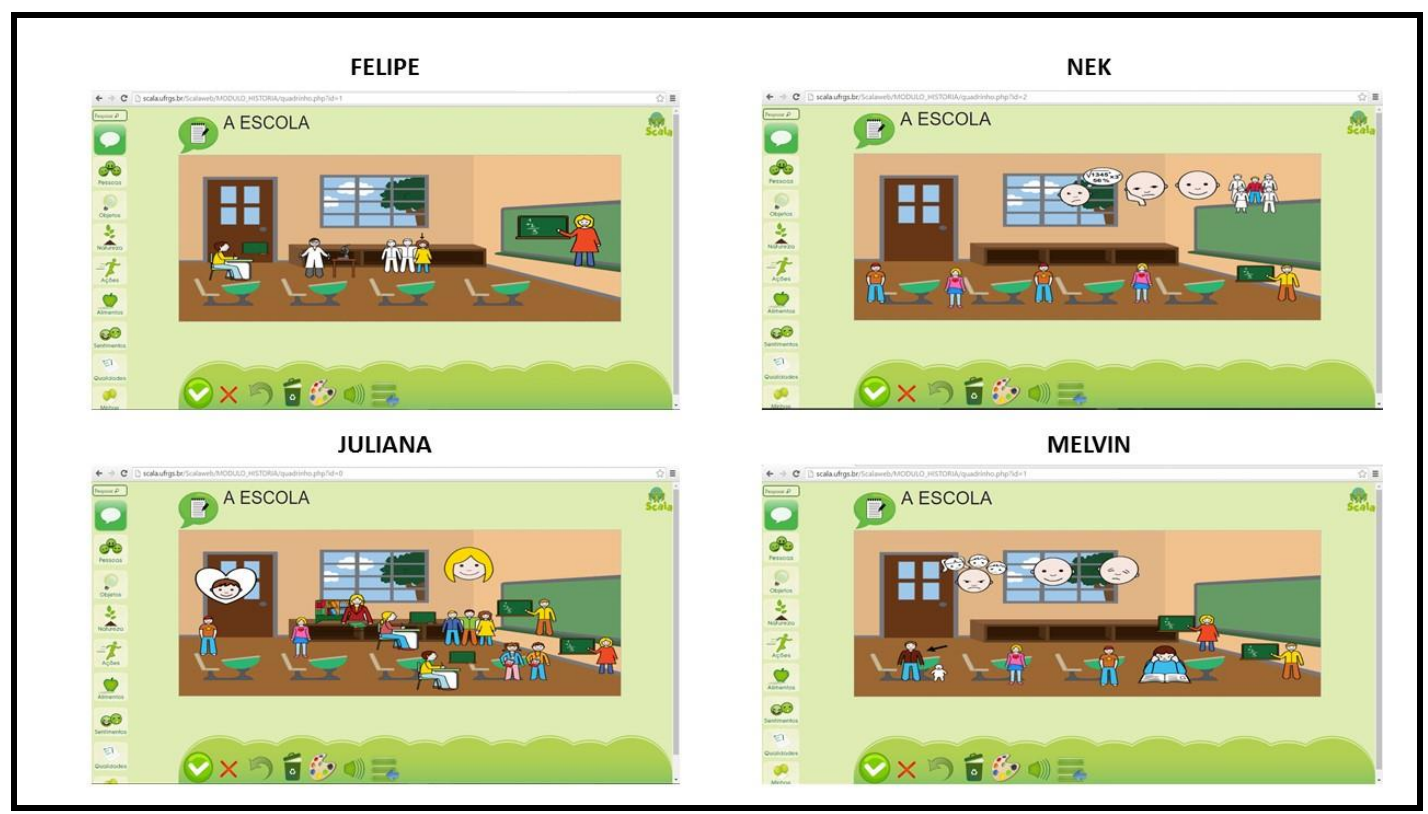

Fonte: http://scala.ufrgs.br 
A tecnologia assistiva scala como recurso para produção de narrativas e registro de dados nas pesquisas em educação: uma experiência com pessoas adultas com transtorno do espectro autista

O cenário de sala de aula foi o mesmo escolhido por todos os participantes, que ainda representaram a si nesse ambiente, seus colegas de turma e professores.

Sobre o espaço escolar, Felipe narrou sua importância, as disciplinas e as amizades construídas e as professoras:

A escola é importante! É onde eu estudo. As escolas, onde eu fiz a educação básica, a gente tinha aula de Química, Física, Biologia... Aí tinha o laboratório... É o lugar aonde a gente faz as amizades. E as professoras... [momento de pausa] a gente não pode ser injusto, né? Não pode discriminar uma em detrimento de outra. Eu sou grato! Os professores não eram muito preparados, porque naquela época, né? Muita pouca coisa sabia em como lidar com aluno especial. E ainda hoje é assim! (FELIPE)

Felipe também expressou suas conquistas e alegrias, bem como preferiu não relatar quanto a possíveis experiências negativas vivenciadas na escola:

Eu nunca repeti de ano, sempre tirava notas boas, assim, todo mundo queria fazer trabalho comigo, queria fazer prova comigo (FELIPE) Se for pra lembrar também não gosto! Não gosto de ficar lembrando sabe? Página virada, bola pra frente! De uma forma geral eu me sentia bem na escola (FELIPE)

Sobre a experiência nesse espaço, Nek representou a si, seus colegas e seus sentimentos quanto às aulas e relatou:

Aqui sou eu, os alunos que não lembro o nome e meu professor. Gostava dos professores da escola. Tinha um amigo. Era difícil a matemática, ficava com tédio. Às vezes feliz, quanto tava com meus colegas (NEK)

Juliana elaborou a história sobre a escola utilizando um cenário de sala de aula e imagens representando a si, seus amigos, professores, biblioteca e seu sentimento quanto a esse espaço. Quanto às imagens, explicou:

Aqui é meu amigo... [referiu o nome], Eu, a biblioteca da escola... eu adorava a biblioteca! Meus colegas... [referiu os nomes], meus amigos, os professores... [referiu os nomes]. Eu me sentia muito feliz. na escola! (JULIANA). 
Sobre as experiências na escola, Melvin contextualizou usando imagens representando a si, colegas, professores e sentimentos, referindo-se à escola em que cursou a sexta série aos trinta anos.

Lá tinha adulto, alunos, eu... e eu estudando matemática. Eu gostava de estudar matemática! Os professores. As vezes era desagradável e ficava cansado. Mas ficava feliz! Eu não gostava de ficar sem fazer nada. Eu gosto de estudar! (MELVIN)

O período de afastamento/interrupção escolar que vivenciaram durante o percurso escolar, devido às dificuldades enfrentadas para a matrícula e permanência, produziu consequências tanto no desenvolvimento, quanto na autoestima dos participantes, pois eles sentiam necessidade da escola e dos amigos, fato evidenciado nas narrativas em que significaram a importância do espaço escolar nas suas vidas:

Eu fui liberada por mim mesma do colégio, deixei os meus amigos sozinhos sem mim... [momento de pausa, baixou a cabeça $e$ entristeceu-se]. Eu não deveria ter saído de lá não! Gosto de estudar. Queria voltar né?. Eu não posso abandonar os meus amigos. Se eu abandonar os meus amigos vai ficar terrível para mim... Se dependesse de mim, eu voltava para ficar por lá o tempo todo da minha vida. Eu tenho as minhas três camisetas do colégio guardadas de lembrança e uma calça. Foi muito bom! Eu gostava da lanchonete, eu fazia atividade... Eu me sentia muito feliz na escola! (JULIANA)

Eu gostava! Gostava dos professores, dos colegas. Eu gostava de aprender, de me divertir bastante. Conversava, gostava dos esportes, dos passeios da escola, de aprender teatrinho, da merenda. Eu não tinha o que não gostar na escola. Fico triste porque saí da escola (MELVIN)

A saída da escola lhes causou rupturas no vínculo com os amigos, pois para os participantes, era o único lugar em que compartilhavam e interagiam com eles.

Melvin foi o único participante que não concluiu o ensino médio, devido às inúmeras dificuldades impostas pelo sistema escolar quanto a sua matrícula e permanência. Juliana concluiu o ensino médio aos vinte e cinco anos, porém, não possui certificado de conclusão devido ao acordo imposto pela escola de que nada fosse exigido para que lhe aceitassem e permanecesse. Nek concluiu aos dezesseis anos e Felipe aos dezoito anos, e ambos prosseguiram para o ensino superior. 
Portanto, assim como dito por Bez e Passerino (2015, p. 18), "o Scala como recurso tecnológico tem promovido habilidades e esquemas de comunicação por meio da tecnologia com aplicabilidade no âmbito da Educação, da família e dos espaços terapêuticos". Isso foi alcançado nessa pesquisa; deste modo, destaca-se a relevância dos dispositivos digitais como busca e apoio na comunicação de sujeitos com TEA e a importância de estratégias, pelo pesquisador, nesse processo relacional, para que os participantes se comuniquem através da disponibilização de tais recursos.

Também provocou, nos participantes com TEA, entusiasmo, satisfação e interesse durante a atividade, como também identificaram Rico, Bez e Passerino (2015) em seus estudos. Essas autoras também defendem ser "necessária uma observação atenta aos sujeitos com TEA, para que se possa perceber o seu grande empenho para serem compreendidos" (p. 125).

Utilizar o módulo de Narrativas Visuais do SCALA permitiu, conforme estudo de Monte, Miranda e Passerino (2015), construir o contexto, possibilitando percepções e significações sobre o tema abordado, sob trajetórias de diferentes olhares, em meio aos valores culturais e atrelados ao contexto social, no ordenar e representar a realidade.

\section{Considerações finais}

Estudos que envolvam participantes com déficits de comunicação ou com TEA produzindo narrativas de vida apoiados à tecnologia assistiva, de comunicação alternativa, com ações mediadoras na construção das referidas narrativas, são pouco explorados nas pesquisas.

Espera-se contribuir na reflexão de necessidade de atenção desses participantes de pesquisa, de forma a possibilitar um espaço para que se expressem, para que possam falar em primeira pessoa sobre assuntos que lhes dizem respeito, pois o sujeito da educação precisa ser ouvido.

$\mathrm{Na}$ particularidade desse artigo, pode-se refletir sobre a importância de disponibilizar um sistema de comunicação alternativa no intuito de aumentar o potencial de comunicação de participantes com TEA, a exemplo do que pode ser alcançado com o uso do SCALA. Essa ferramenta pode ser empregada por pesquisadores interessados em compreender as vivências escolares dos indivíduos e as suas relações, motivações e percepções com as práticas do sistema escolar. 
O uso do SCALA nesse estudo proporcionou conhecer as percepções dos participantes com TEA quanto aos professores, escola e amigos, seus interesses e dificuldades, experiências positivas e negativas e sentimentos quanto à interrupção do processo de escolarização, indicando a necessidade de desdobramento de novas pesquisas nesse âmbito para integrar as teorias relacionadas ao aluno com TEA.

\section{REFERÊNCIAS}

CLANDININ, D. J.; CONNELLY, F. M. Pesquisa narrativa: experiência e história em pesquisa qualitativa. Tradução: Grupo de Pesquisa Narrativa e Educação de Professores ILEEI/UFU. 2. ed. rev. Uberlândia: EDUFU. 250 p., 2015.

BEZ, M. R. et al. Desenvolvimento de narrativas visuais no SCALA: estudo de caso de uma turma de inclusão da Educação Infantil. Informática na Educação: teoria e prática. Porto Alegre, v. 16, n. 2, jul./dez, 2013.

BEZ, M. R.; PASSERINO, L. M. Perspectiva histórica do Scala. In: Comunicação alternativa: mediação para uma inclusão social a partir do SCALA [recurso eletrônico]. Liliana Maria Passerino, Maria Rosangela Bez (Org.). Passo fundo: Ed. Universidade de Passo Fundo, 2015.

BEZ, M. R.; PASSERINO, L. M. Scala 2.0: software de comunicação alternativa para web. AVANCES Investigación en Ingeniería, v. 9, n. 1, 2012.

DILLON, G.; UNDERWOOD, J. FREEMANTLE, L. Autism and the U.K. secondary school experience. Focus on Autism and Other Developmental Disabilities, p 1-10, 2014.

HICKEY, A.; CRABTREE, J.; STOTT, J. 'Suddenly the first fifty years of my life made sense': experiences of older people with autism. Autism, p. 1-11, 2017.

MONTE, B. T.; MIRANDA, H.; PASSERINO, L. M. Dos personagens aos livros: processos e estratégias do contar histórias. In: Comunicação alternativa: mediação para uma inclusão social a partir do SCALA [recurso eletrônico]. Liliana Maria Passerino, Maria Rosangela Bez (Org.). Passo fundo: Ed. Universidade de Passo Fundo, 2015.

RICO, A.; BEZ, M. R.; PASSERINO, L. M. Estudo investigativo: emprego do Scala, no módulo Narrativas Visuais, em contexto de turma inclusiva da educação infantil. In: Comunicação alternativa: mediação para uma inclusão social a partir do SCALA [recurso eletrônico]. Liliana Maria Passerino, Maria Rosangela Bez (Org.). Passo fundo: Ed. Universidade de Passo Fundo, 2015.

PASSERINO, L. M.; BEZ, M. R. Sobre comunicação e linguagem. In: Comunicação alternativa: mediação para uma inclusão social a partir do SCALA [recurso eletrônico]. 
Liliana Maria Passerino, Maria Rosangela Bez (Org.). Passo fundo: Ed. Universidade de Passo Fundo, 2015.

PASSERINO, L. M. et al. SCALA e Siesta Cloud: uma integração para aplicações homeschooling visando a inclusão. Anais do II Congresso Brasileiro de Informática na Educação (CBIE 2013) e XXIV Simpósio Brasileiro de Informática na Educação (SBIE 2013), 2013.

PREECE, D.; JORDAN, R. Obtaining the views of children and young people with autism spectrum disorders about their experience of daily life and social care support. British Journal of Learning Disabilities. 2010.

SILVA, D; TRENTINI, M. Narrativas como técnica de pesquisa em enfermagem. Rev Latino-am Enfermagem, maio-junho; v. 10, n. 3, p. 423-432, 2002.

\section{Como referenciar este artigo}

BITTENCOURT, Ivanise Gomes de Souza.; FUMES, Neiza de Lourdes Frederico. A tecnologia assistiva scala como recurso para produção de narrativas e registro de dados nas pesquisas em educação: uma experiência com pessoas adultas com transtorno do espectro autista. Revista Ibero-Americana de Estudos em Educação, Araraquara, v. 12, n. esp. 2, p. 1481-1495, ago./2017. Disponível em: <http://dx.doi.org/10.21723/riaee.v12.n.esp.2.1304>. E-ISSN: 1982-5587.

Submetido em: 10/03/2017

Aprovação final em: 15/08/2017 